\title{
Year-round distribution and habitat preferences of the Bugio petrel
}

\author{
Iván Ramírez ${ }^{1, *}$, Vitor H. Paiva ${ }^{2}$, Dilia Menezes ${ }^{3}$, Isamberto Silva ${ }^{3}$, \\ Richard A. Phillips ${ }^{4}$, Jaime A. Ramos ${ }^{2}$, Stefan Garthe ${ }^{5}$
}

\author{
${ }^{1}$ SPEA-Portuguese Society for the Study of Birds, Avenida João Crisostomo No18 4Dta, Lisboa 1000-179, Portugal \\ ${ }^{2}$ Institute of Marine Research (IMAR/CMA), Department of Life Sciences, University of Coimbra, Apartado 3046, \\ Coimbra 3001-401, Portugal \\ ${ }^{3}$ Parque Natural da Madeira, Quinta do Bom Sucesso, Caminho do Meio, Funchal 9050-251, Madeira, Portugal \\ ${ }^{4}$ British Antarctic Survey, Natural Environment Research Council, High Cross, Madingley Road, Cambridge CB3 0ET, \\ United Kingdom \\ ${ }^{5}$ Research and Technology Centre (FTZ), University of Kiel, Hafentörn 1, 25761 Büsum, Germany
}

\begin{abstract}
The conservation of threatened seabirds that are highly pelagic, such as the gadfly petrels Pterodroma spp., depends on understanding the main oceanographic determinants of their movements in order to apply the necessary management regulations and to identify and protect their key marine habitats. The present work presents for the first time information on the distribution and habitat preferences of 17 Bugio petrels Pterodroma deserta from the island of Bugio, Madeira archipelago, North Atlantic Ocean. All of the birds remained in North Atlantic waters during the pre-laying exodus, incubation and chick-rearing periods, showing a clear preference for deep, productive (high chlorophyll a levels) waters north of the Azores archipelago. There was high individual variability in migration strategies. Five wintering areas were identified: two off the Brazilian coast, one around the Cape Verde archipelago, one off the southeast coast of the United States, and one in pelagic waters in the central South Atlantic. These tended to be areas of high productivity but not of a particular sea surface temperature regime. Based on saltwater immersion data, birds were more active during the breeding season and spent more time resting on the water in wintering areas. There was also a positive correlation between the time spent on the water and the progression of full to new moon, suggesting that the birds may use moonlight to search for prey. Given its highly dispersed distribution at sea throughout the year, effective conservation of this threatened species may require management at large spatial scales.
\end{abstract}

KEY WORDS: Atlantic Ocean - Pelagic seabird · Petrels · Marine habitat use - Migration · Conservation management

Resale or republication not permitted without written consent of the publisher

\section{INTRODUCTION}

Pelagic marine predators, in particular seabirds, have declined worldwide due to degradation of breeding habitat, impacts of introduced predators, overexploitation of marine resources, incidental mortality in fisheries and, to a lesser extent, climate variability (e.g. Anderson et al. 2011). The management and conservation of highly migratory marine taxa depends on understanding how movements relate to ocean processes, together with assessing the poten- tial human-related threats occurring in the areas occupied by the taxa (Block et al. 2011). Although several types of tracking devices are now used routinely to monitor the movements of large seabirds, there is comparatively little published information for small, pelagic species, in particular the gadfly petrels Pterodroma spp. (but see Rayner et al. 2010, 2012, Pinet et al. 2011b, Zino et al. 2011).

For most species of gadfly petrels, knowledge of atsea distribution remains limited to shipboard observations, coastal counts or aerial surveys, and ring recov- 
eries. However, understanding the foraging behaviour and habitat preferences of gadfly petrels with these traditional methods has always been a logistical challenge because they rarely congregate at sea and, therefore, are only observed in very low densities away from colonies (Ramírez et al. 2008, Arcos et al. 2009). Moreover, the impacts of introduced predators and degradation of breeding habitat have resulted in long-term population declines, such that many species only persist as very small, isolated populations.

One of the rarest Pterodroma species in the world is the Bugio petrel P. deserta (see Jesus et al. 2009 regarding the genetic separation of this species), ), a medium-sized pelagic seabird that breeds only on the south plateau of Bugio island, one of the 3 islands that form the Desertas archipelago (Madeira). This bird has only recently been monitored extensively thanks to the efforts led by the Madeiran Natural Park authorities and the support of several institutions, such as the Portuguese BirdLife Partner, SPEA. Since 2004, the Bugio petrel has been monitored intensively, as described by Menezes et al. (2010). It has a current population size of 160 to 180 breeding pairs (D. Menezes unpubl. data) and a trend that is considered to be stable. Breeding occurs between early June and mid-November, when both parents perform incubation shifts and later provision the chick nocturnally. The outward migrations start around 20 November, and wintering grounds are usually reached $\sim 10 \mathrm{~d}$ later. The return migration usually starts in the second week of May (Menezes et al. 2010).

The at-sea distribution of Pterodroma deserta was assessed using ship-based surveys over the period from 2005 to 2010 (Ramírez et al. 2008, I. Ramírez pers. comm). Despite the large survey effort, totalling $2243 \mathrm{~h}$ and covering an area of $9602 \mathrm{~km}^{2}$ (Menezes et al. 2010, I. Ramírez unpubl. data), only 812 out of 102414 seabird records $(0.8 \%)$ were of the 2 Pterodroma species breeding in the Madeira archipelago (Madeiran petrel P. madeira and Bugio petrel), which, moreover, are very difficult or impossible to differentiate at sea. Nevertheless, these data allowed the designation of a Marine Important Bird Area (PTM16-Desertas) in 2008, which was presumed to cover some of the key areas used by breeding birds (Ramírez et al. 2008). Previous studies of the movements of Pterodroma species clearly indicate that they disperse over large ocean areas, even during the breeding season (MacLeod et al. 2008, Rayner et al. 2008, Pinet et al. 2012) and are highly migratory (Pinet et al. 2011b, Rayner et al. 2011, 2012). Given the lack of information on the location of core habitat for the Bugio petrels beyond the boundary of the ship surveys, including areas used during the nonbreeding period, the purpose of the present study was to analyse the at-sea distribution, movements and activity patterns of Bugio petrels tracked year-round. The main objectives were to determine the timing of movements; identify the main foraging areas used during the breeding season, on stopovers during migration and during the winter; assess the environmental characteristics (depth, chlorophyll a concentration and sea surface temperature) of these key areas; and examine variation among individuals and years in migration strategies.

\section{MATERIALS AND METHODS}

\section{Study site and logger deployment}

Fieldwork was conducted at Bugio Island $\left(32^{\circ} 25^{\prime} \mathrm{N}, 16^{\circ} 29^{\prime} \mathrm{W}\right)$, Madeira archipelago, in the east North Atlantic Ocean. The Bugio petrel breeds exclusively at the south plateau of this island, ca. $400 \mathrm{~m}$ above sea level, within an area of 2.2 ha. Between late June and mid-July in 2007 to 2010, a total of 24 combined GLS-immersion loggers weighing $1.5 \mathrm{~g}$ (MK14; British Antarctic Survey, Cambridge) were deployed. A single cable-tie was used to secure each logger on a thin bed of silicone sealant to a metal ring on the tarsus of each bird. Some abrasion of the tarsus caused by the attachment was noted during the first year of tracking (2007 to 2008) but was remedied in subsequent years by use of a larger ring size. The logger plus attachment represented 2.0 to $2.6 \%$ of adult mass, which is less than the threshold beyond which deleterious effects on trip duration may be observed (Phillips et al. 2003). All birds were captured at their nests during daylight hours in the pre-laying period and were returned to their burrows after logger attachment, an operation that usually did not take longer than $5 \mathrm{~min}$. All birds were weighed at logger deployment and retrieval.

Loggers were only fitted to previously ringed birds in well-established breeding pairs in the first 2 seasons to maximise the likelihood of recapture. As part of the habitat restoration works at the plateau, artificial breeding chambers were built, and we began tracking individuals from these nests in 2009. All active nests were visited both during daylight and darkness in the years following logger deployment, and most devices were recovered after a single year. Visits to deploy and retrieve the devices occurred in late June or early July (range 20 June to 10 July) (i.e. 
during the pre-laying phase). To assess the effect of loggers, we compared the breeding success of tracked birds and untagged controls through several visits to the colony, accompanying the breeding outcome from egg incubation to chick fledging. This continuous monitoring was possible because of the habitat restoration work being conducted by the LIFE project 'SOS Freira do Bugio'.

\section{Interpretation of behaviour}

The devices recorded light (for geolocation) and salt-water immersion (for analysis of activity). Geolocation is the calculation of position (twice per day) from ambient light level readings with reference to time. Latitude and longitude were estimated from day (night) length and the time of local midday (midnight), respectively, in relation to Greenwich time (Phillips et al. 2004). Data were analysed using the BASTrack software suite, using a light threshold of 10 and an elevation angle of -4.7 (Phillips et al. 2004). The quality of the light curves was high, so the geolocation error was assumed to be similar to that estimated by Phillips et al. (2004), even though those measurements were collected at higher latitudes (Phillips et al. 2004). Locations derived from curves with apparent interruptions around sunset and sunrise were removed. Erroneous locations were also excluded for several weeks around the equinoxes, when latitudes are unreliable. Locations were also removed if they represented unrealistic flying speeds (>10 $\mathrm{m} \mathrm{s}^{-1}$ sustained over a $48 \mathrm{~h}$ period), using bespoke software routines written in $\mathrm{R}$ ( $\mathrm{R}$ Development Core Team 2011). Validated data were smoothed twice (Phillips et al. 2004).

The activity patterns of Bugio petrels were derived from both immersion and light level data recorded for each bird. The loggers tested for saltwater immersion every $3 \mathrm{~s}$ using 2 electrodes and stored the number of positive tests from 0 (continuously dry) to 200 (continuously wet) at the end of each $10 \mathrm{~min}$ period. The loggers also measured light level every minute and stored the maximum (truncated at a value of 64) at the end of each 10 min period. The immersion data were categorised into day and night (based on the light data) representing the proportion of time spent on the sea surface (as distinct from flying or on land) during day and night. Time budget calculations excluded periods spent in burrows (prolonged periods of darkness and dry records). Periods that the birds spent on the water surface were identified as any contin- uous sequence of 10 min blocks with at least 3 s sitting on the water, while a continuous sequence of dry (0) values was considered as a flight bout (see Phalan et al. 2007, Mackley et al. 2011). Light and activity (immersion) data were used simultaneously to distinguish time spent at sea from time in the colony (burrows) and hence colony attendance patterns. These patterns and the duration of foraging trips, identified based on the logger data, were also confirmed on the ground by monitoring the burrow visits of the telemetered individuals.

These data were analysed using customised functions and functions within the 'adehabitat' package in R (Calenge 2006) to extract accurate information on at-sea activity patterns and the timing of breeding events.

\section{Spatial analyses}

Kernel density estimates were generated from the geolocation data in an Albers equal-area conic projection with a smoothing parameter $(h)$ of $200 \mathrm{~km}$ and a $100 \mathrm{~km}$ grid size. The $h$ value approximates the mean accuracy of these devices (Phillips et al. 2004). Following previous authors (e.g. Paiva et al. 2010a), we considered the $50 \%$ and $95 \%$ kernel density contours to represent the core area of activity and the area of active use, respectively.

The yearly life cycle of the Bugio petrel was split into 4 major phases: (1) breeding period (from first return to the colony after the winter to the last day before outward migration), (2) winter migration (between the breeding grounds and major wintering area, represented by the respective $50 \%$ kernel polygons), (3) the wintering period (from arrival at to departure from the main wintering area) and (4) the return migration (from the main wintering area back to the breeding grounds). Stopover areas were identified as the $50 \%$ kernel density contour of the geolocations of Phases 2 and 4 . The $95 \%$ kernels of the former geolocations (i.e. excluding the $50 \%$ kernel regions) were considered to represent rapid migratory movements by birds in transit, as opposed to the former stopover periods, when birds are supposed to increase their residence in order to build up energetic reserves.

\section{Environmental characteristics}

To characterise the oceanographic conditions in areas used by the tracked birds, we determined the 
seafloor depth (DEPT, m), chlorophyll a concentration (CHLA, $\mathrm{mg} \mathrm{m}^{-3}$ ) at the sea surface, sea surface temperature $\left(\mathrm{SST}^{\circ}{ }^{\circ} \mathrm{C}\right)$, gradients in these 3 variables (SLOP, CHLG and SSTG, respectively) and wind speed (WIND, $\mathrm{m} \mathrm{s}^{-1}$ ). We also computed distance to the breeding colony (DCOL, $\mathrm{m}$ ) as a measure of the central-place foraging constraint during the breeding period. In addition, distance to land (DLAN, m) was included in the models during the wintering phase. All remote sensing products were downloaded from http://coastwatch.pfeg.noaa.gov/coastwatch/CWBrowserWW180.jsp. DEPT (an ETOPO 1 product) was extracted at a spatial resolution of $0.01^{\circ}$. Monthly composites of both CHLA and SST were used for the period between July 2007 and July 2010. Aqua moderate resolution imaging spectrometer (Aqua MODIS) products of CHLA and SST (dynamic variables) were downloaded at a spatial resolution of $0.04^{\circ}(\sim 4 \mathrm{~km})$. Monthly averages of WIND were also used as environmental predictors. These products were extracted for a grid of $0.25^{\circ}$ $(\sim 25 \mathrm{~km})$. Mean values and, as appropriate, gradients in environmental variables were computed in ArcGIS 9.2. For instance, gradients in CHLA were determined by estimating rates of change per $0.1^{\circ}$ grid square and by moving a window function $\left(0.3^{\circ}\right.$ wide ; function $=[(\max$. value - min. value $) \times$ 100]/(max. value)) using ArcGIS Spatial Analyst. Fronts, as zones of strong CHLA variations, will appear more clearly when using CHLG than using CHLA values alone. Gradient in depth was used as a proxy of slope (SLOP).

\section{Habitat use models}

Three habitat use models were constructed explaining the habitat affinities of birds during the (1) wintering, (2) pre-laying and incubation, and (3) chick-rearing phases. Points inside the individual kernels of each bird during those 3 different phases (i.e. 1 kernel analysis per phase) were used as the basis to construct the models. Geolocation data were transformed from points to raster, into a mask grid of $1^{\circ}$. Each cell was coded as 1 if it was inside the $50 \%$ kernel density contour or 0 if between the $50 \%$ and $95 \%$ density contours, creating a dichotomous response variable (core habitat vs. peripheral range). To ensure that the models were balanced, an occupied cell in the peripheral range was selected at random for every occupied cell in the core habitat within the distribution of individual birds. Each environmental predictor was then aggregated to match a standard spatial grid of $1^{\circ}$ (i.e. the approximate error of the geolocation method) (Phillips et al. 2004). Environmental variables were not normally distributed, and aggregation was based on the median value, which is a measure of central tendency that is least influenced by outliers (Zuur et al. 2007). All environmental variables were standardised to have a mean of 0 and an SD of 1. Thus, the coefficients of different habitat use models could be compared directly to determine the relative importance of each variable. Environmental variables were first checked for collinearity by computing all pairwise Spearman rank correlation coefficients $\left(r_{\mathrm{s}}\right)$ (Zuur et al. 2007). One of each pairwise highly correlated variables (i.e. $\left|r_{\mathrm{s}}\right|>0.5$ ) was excluded from the model (see Table S2 in the supplement at www.int-res.com/ articles/suppl/m476p269_supp.pdf). The variable to exclude (from each pair) was selected based on the highest Akaike information criterion (AIC; Burnham \& Anderson 2002) (meaning the variable explaining less deviance) after the univariate model was run.

Generalised linear mixed models (GLMMs) were then built using the 'lme4' package (Bates et al. 2008) to relate habitat use with oceanographic variables, accounting for the non-independence of the points belonging to the same individual. Habitat use (occupied cells coded as 0 or 1) was included as the response term fitted with a binomial error distribution (logit link). Uncorrelated or weakly correlated habitat variables (CHLA, SST, DEPT and their gradients, WIND, DCOL and DLAN) were included as fixed effects and retained only if they improved model fit. Trip identity nested within individual was included as a random effect in all models to account for the hierarchical structure of the data. The maximum likelihood method was used to compare models with different fixed effects structures. The AIC value and an ANOVA function were used to compare and rank models with different fixedeffect structures. $\triangle \mathrm{AIC}$ (i.e. the difference between the estimated AIC of the final model and the estimated AIC of the previous model) and the Akaike weight (wi) were also used as a measure of the model fit and relative likelihood of candidate models. All possible combinations of main effects were considered, and final models were interpreted according to the sign and value of the model coefficients for the selected environmental variables.

To test habitat use inside stopover regions (50\% kernel density contours of migratory periods) in relation to the remain migratory period (95\% kernel density contours of migratory periods, excluding the 
$50 \%$ kernel area), $\chi^{2}$ tests were used with at-sea activity (time of residence, time on water, flight speed, mean travel distance) and environmental (DEPT, SST, CHLA and WIND) parameters as dependent variables and kernel contour (i.e. 50\%, inside stopover area, and 51 to $95 \%$ kernels, outside stopover area) as an independent variable.

All variables were examined visually for normality (using quantile-quantile plots) and homoscedasticity (using Cleveland dotplots) before each statistical test. All statistical analyses were performed using the software R. Computations were carried out using several functions within different R packages (e.g. MASS, maptools, adehabitat, sp, proj4 and lme4) and some custom-built functions. Year was initially included as a factor in all analyses but was excluded from final models because in all cases its effect was non-significant $(\mathrm{p}>0.45)$. Pearson's $\chi^{2}$ test with Yates' continuity correction was used to test for differences in breeding success between the nests where birds were fitted with loggers and the controls. Results are given as means $( \pm 1$ SD) with a significance level at $\mathrm{p}<0.05$.

\section{RESULTS}

\section{Logger retrieval and device effects}

In total, 17 out of 24 loggers were retrieved (70\% recovery rate). The average percentage $( \pm 1 \mathrm{SD})$ of locations retained per individual was $77.3 \pm 5.2 \%$, which corresponded to $628 \pm 72.7$ locations per bird. Most of the excluded locations ( 19\%) corresponded to the equinox periods (i.e. around March 20 and September 22) (see Table S1 in the supplement at www.int-res.com/articles/suppl/m476p269_supp.pdf). There was no significant difference in breeding success (chicks fledged per eggs laid) at nests where a bird was tracked $(\mathrm{n}=20)$ and controls $(\mathrm{n}=20)(59.2 \%$ and $50.3 \%$, respectively; $\left.\chi_{1}^{2}=0.10, \mathrm{p}=0.75\right)$.

\section{Breeding distribution}

Foraging distribution changed during the course of the breeding season from 3 June $( \pm 8$ d) to 19 November $( \pm 12$ d) (see Fig. S1 in the supplement at

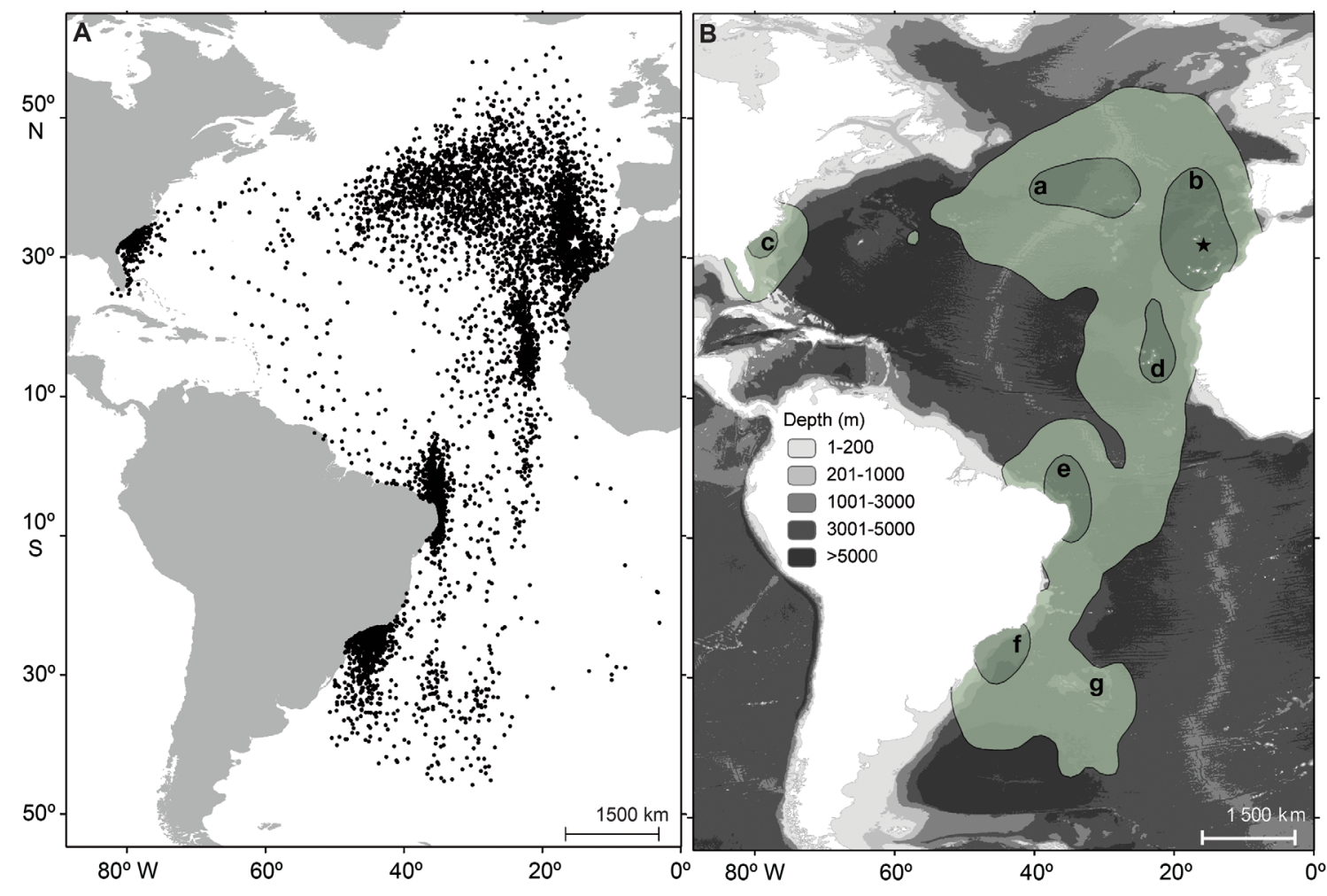

Fig. 1. (A) Locations of all Bugio petrels ( $N=17$ ) tracked from Bugio, Madeira, from 2007 to 2010 and (B) the $95 \%$ (i.e. area of active use, light green) and $50 \%$ (i.e. core area of activity, dark green) kernel density polygons of tracked birds overlaid on seafloor depth. Core areas are as follows: (a) pre-laying and incubation, and (b) chick-rearing; the 5 main wintering grounds are (c) Gulf Stream Current, (d) North Equatorial Current, (e) North Brazil Current, (f) South Brazil Current and (g) central South Atlantic; $(\star)$ Bugio islet (breeding colony) 


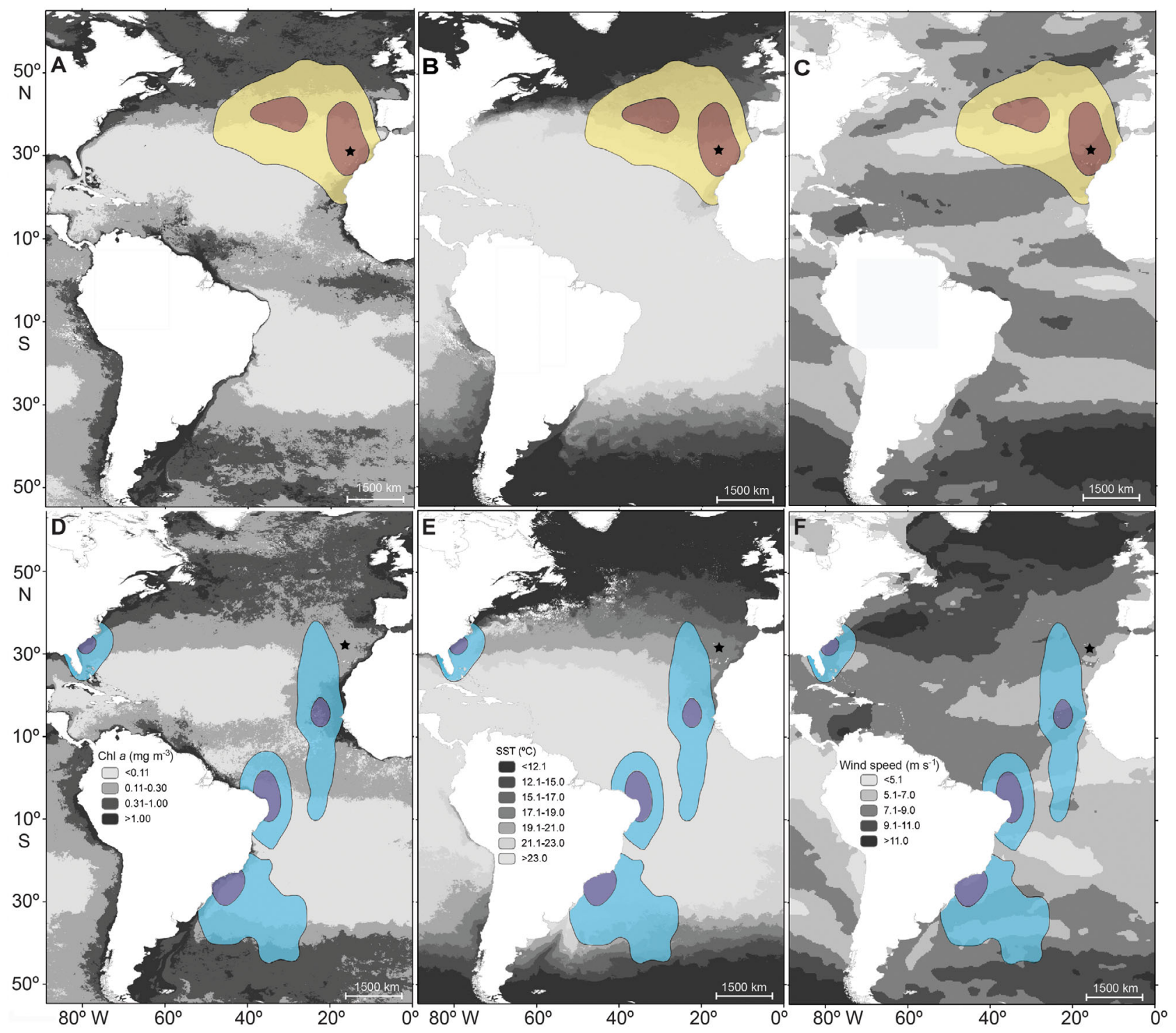

Fig. 2. The $95 \%$ (yellow [A-C] or blue [D-F]) and 50\% (brown [A-C] or purple [D-F]) kernel density polygon of Bugio petrels tracked from Bugio, Madeira, from 2007 to 2010 during (A-C) breeding and (D-F) wintering periods. Kernels are overlaid on $(A, D)$ chlorophyll a concentration $\left(\mathrm{chl} a, \mathrm{mg} \mathrm{m}^{-3}\right),(B, E)$ sea surface temperature $\left(\mathrm{SST},{ }^{\circ} \mathrm{C}\right)$ and $(\mathrm{C}, \mathrm{F})$ wind speed $\left(\mathrm{m} \mathrm{s}^{-1}\right)$. Environmental variables are mean composites for the breeding (June to November) and wintering (December to May) periods. ( $\star$ ) Bugio Islet (breeding colony)

www.int-res.com/articles/suppl/m476p269_supp.pdf). During pre-laying and incubation, tracked birds largely utilised an area of deep water in the north and northwest Atlantic, as far as $50^{\circ} \mathrm{N}$ and $47^{\circ} \mathrm{W}$ (Fig. 1). During incubation, between 14 July $( \pm 7 \mathrm{~d})$ and 29 August $( \pm 9 \mathrm{~d})$, birds spent a mean of $9.3 \pm$ $6.2 \mathrm{~d}$ foraging at sea between shifts at the nest. During chick-rearing, the distribution moved to waters closer to the breeding colony, between deep water north of Madeira (up to $39^{\circ} \mathrm{N}$ ) and the Canary upwelling system off the northwest African coast (Figs. $1 \& 2$ ). The duration of trips during chick- rearing varied among individuals and was generally bimodal. Short trips $(<3 \mathrm{~d})$ lasted on average $1.78 \pm$ $0.81 \mathrm{~d}$, while long excursions ( $>4 \mathrm{~d}$ ) took on average $10.21 \pm 3.45 \mathrm{~d}$. The environmental characteristics of core habitats selected by birds (i.e. within the $50 \%$ kernel density contour) were different from those of peripheral areas (between the $50 \%$ and $95 \%$ contours) (Fig. 2). Specifically, during pre-laying and incubation, birds seemed to prefer pelagic frontal regimes (both CHLG and SSTG were selected in the models), areas of high wind and deep water. During the chick-rearing phase, birds mostly exploited areas 
with high productivity regimes (CHLA) that were relatively cold and shallow. During this period, the further away the birds were from the colony (i.e. higher DCOL values), the less probable it was to find a core habitat (see Table 1 for more details).

\section{Migrations and stopover sites}

Birds started their outward and return migrations on 19 November $( \pm 12 \mathrm{~d})$ and 12 May $( \pm 8 \mathrm{~d})$, respectively. The duration of each migration period varied according to the wintering destination; birds wintering around the North Equatorial Current travelled fewer days than those wintering in other regions (see Table S1 in the supplement). Main stopover areas on the outward migration were broadly located around Cape Verde and off northeast Brazil and were utilised by $66.7 \%$ and $41.7 \%$ of tracked individuals, respectively (Fig. 3A). During the return migration, stopover areas were mostly to the northwest of the Azores, where the Gulf Stream Current meets the

Table 1. Habitat use models (GLMMs) of Bugio petrels during the non-breeding (winter) and breeding (pre-laying and incubation as well as chick-rearing) phases. Values in the table are the coefficients $(\beta \pm \mathrm{SE})$ of the variables included in the top-ranked models. All main effects were tested, and those that were significant are presented in bold. AIC: Akaike's information criterion; wi: Akaike weight; AUC: area under the receiving operating characteristics (ROC) curve; (-) independent variable not included in the model due to collinearity with other covariates. For definition of variables, see 'Materials and methods: Habitat use models'

\begin{tabular}{|lccc|}
\hline $\begin{array}{l}\text { Environmental } \\
\text { variables }\end{array}$ & $\begin{array}{c}\text { Pre-laying and } \\
\text { incubation }\end{array}$ & $\begin{array}{c}\text { Chick- } \\
\text { rearing }\end{array}$ & Wintering \\
\hline Constant & $-1.451 \pm 0.082$ & $-0.732 \pm 0.024$ & $-1.012 \pm 0.65$ \\
Dynamic & & & - \\
Chlorophyll a (CHLA) & $0.013 \pm 0.042$ & $\mathbf{0 . 6 7 9} \pm \mathbf{0 . 0 8 7}$ & - \\
CHLA gradient (CHLG) & $\mathbf{0 . 7 6 7} \pm \mathbf{0 . 0 7 1}$ & - & $0.09 \pm 0.03$ \\
Sea surface temperature (SST) & - & $\mathbf{- 0 . 2 9 3} \pm \mathbf{0 . 0 1 3}$ & $\mathbf{- 0 . 5 8 4} \pm \mathbf{0 . 0 5 7}$ \\
SST gradient (SSTG) & $\mathbf{- 0 . 3 9 2} \pm \mathbf{0 . 0 6 3}$ & - & - \\
Wind speed (WIND) & $\mathbf{0 . 7 6 2} \pm \mathbf{0 . 0 1 1}$ & $0.016 \pm 0.012$ & $\mathbf{0 . 4 6 2} \pm \mathbf{0 . 0 1 2}$ \\
Static & & & - \\
Sea depth (DEPT) & $\mathbf{- 0 . 1 0 2} \pm \mathbf{0 . 0 2 5}$ & $\mathbf{0 . 2 2 4} \pm \mathbf{0 . 1 6 3}$ & - \\
Sea basin slope (SLOP) & $0.019 \pm 0.072$ & $\mathbf{0 . 8 3 4} \pm \mathbf{0 . 0 3 2}$ \\
Distance to land (DLAN) & $\mathbf{- 0 . 1 2 1} \pm \mathbf{0 . 0 1 6}$ & $\mathbf{- 0 . 3 5 3} \pm \mathbf{0 . 0 4 6}$ & $\mathbf{- 0 . 2 4 1} \pm \mathbf{0 . 0 2 2}$ \\
& & & 187.14 \\
AIC & 255.23 & 194.12 & 1.87 \\
$\Delta$ AIC & 1.22 & 1.38 & 0.47 \\
wi (AIC weight) & 0.55 & 0.47 & 74.15 \\
AUC (\%) & 89.13 & 91.45 & \\
aFor the habitat models of the breeding period (pre-laying and incubation \\
as well as chick-rearing), 'distance to land' was replaced by 'distance to \\
colony' to represent the effect of the central-place foraging strategy on the \\
habitat utilisation patterns by breeding adults & \\
\hline
\end{tabular}

Arctic Current, and close to the mid-Atlantic ridge (an area used by $50.0 \%$ of tracked birds), and one other small area was off the north coast of Brazil (exploited by $16.7 \%$ of birds) (Fig. 3B). During the outward migration, birds actively selected stopover areas $(50 \%$ kernel density contours) with significantly higher chl $a$ and lower depth than the remaining habitats used during the migration (i.e. the $95 \%$ kernel density contours). On the return migration, birds also selected productive (higher chl a), relatively cold waters that were also windy in comparison to sites on the remaining migratory route (Table 2 ).

\section{Wintering distribution}

Bugio petrels $(n=12)$ were resident in their core wintering areas on average $( \pm 1 \mathrm{SD})$ from $29 \mathrm{Nov}$ ( $\pm 11 \mathrm{~d})$ to 12 May ( $\pm 8 \mathrm{~d}$ ). These areas were (1) around the Gulf Stream Current in the Beaufort valley off the coasts of Florida and Georgia, mainly in neritic water ( $<200 \mathrm{~m}$ depth, continental shelf) $(\mathrm{n}=1$ of the tracked population); (2) the North Equatorial Current around the Cape Verde archipelago, mainly in oceanic waters (>200 m depth) $(\mathrm{n}=3)$; (3) the northward extension of the Brazil Current, an area that encompasses both neritic and oceanic environments off the coasts of the Brazilian states of Ceará, Rio Grande do Norte, Paraiba and Pernanbuco $(\mathrm{n}=3)$; (4) the southern Brazil Current, an area of mainly neritic but also some oceanic waters around the Tropic of Capricorn $(\mathrm{n}=4)$; and (5) the Central South Atlantic, exclusively oceanic waters south of the Rio Grande Oceanic Rise ( $n=1)$ (Fig. 1 and Bird PF0024 in Fig. 4). While on their wintering grounds, birds actively selected (in degree of preference based on the coefficient value on Table 1) foraging grounds with low depth, low SST, high wind speed and short distances to land (Table 1). Oceanographic regimes differed among these 5 main wintering grounds (Table 2). All were characterised by low SST values. While near the Gulf Stream Current, birds used areas of significantly higher productivity (CHLA), lower SST and steeper slope that were closer to the coast. The chl a 


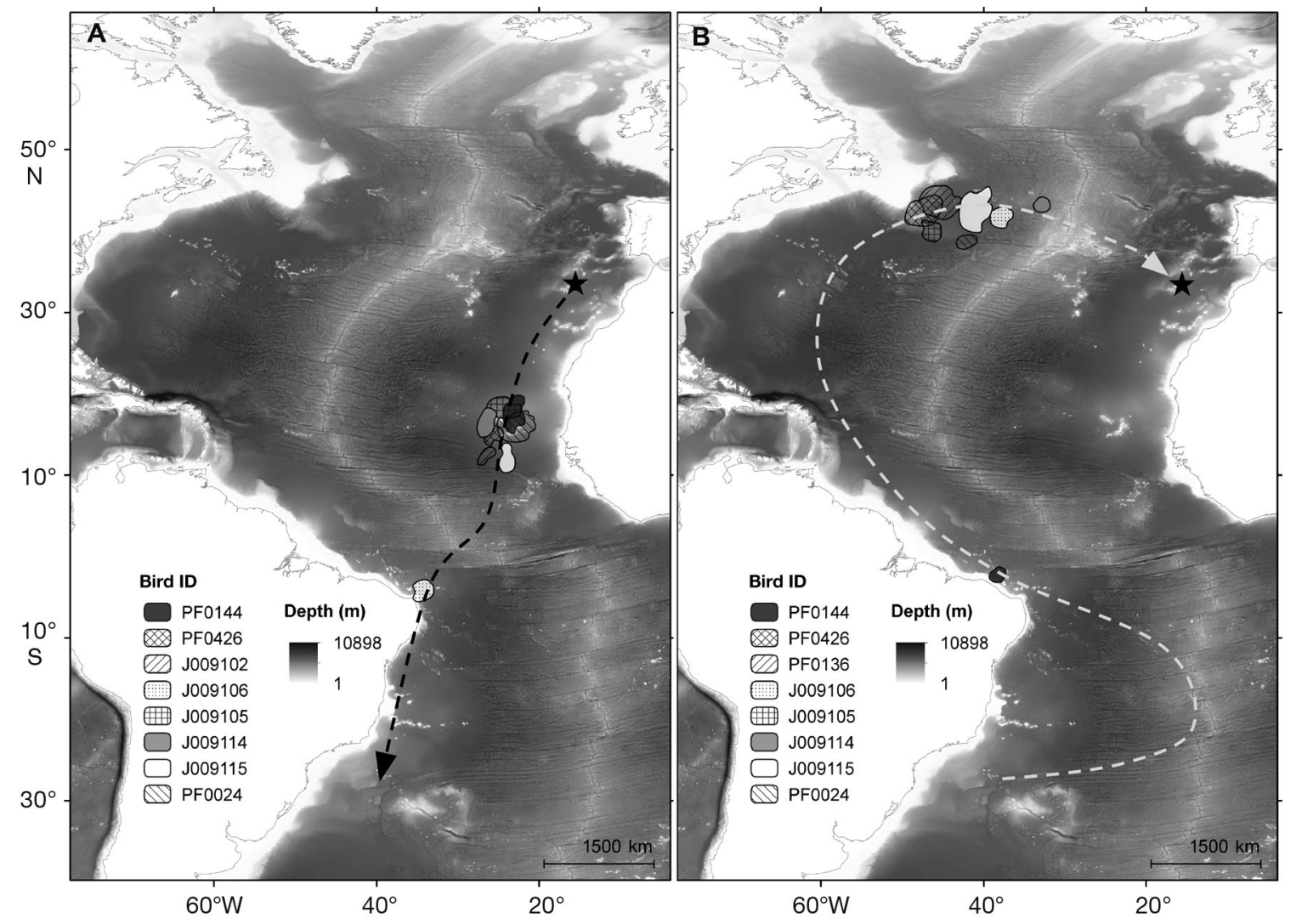

Fig. 3. Core areas (50\% kernel contours) of individual migration-stopover locations for Bugio petrels $(\mathrm{n}=8)$ tracked from Bugio, Madeira, from 2007 to 2010. (A) Outward migration of birds that wintered in the South Brazil Current (mid-December) and (B) return migration (mid-May). $\star$ : Bugio islet (breeding colony)

concentration was relatively high and SST low in the wintering area around the North Equatorial Current. The wintering grounds of the Northern Brazil Current and Southern Brazil Current were characterised by lower SST values, higher slopes and greater proximity to land. Core habitats in the Central South Atlantic wintering area were characterised by steeper gradients in both CHLA and SST and strong winds.

\section{At-sea activity patterns}

The proportion of time spent on the water varied greatly by year, between daylight and darkness and among individuals (Fig. 4). The proportion spent on the water was always higher during the day than during the night (based on the GLMM: breeding period: $\chi_{1}^{2}=18.56, \mathrm{p}<0.001$; wintering
Table 2. Comparison of at-sea activity patterns and oceanographic characteristics of stopover regions (i.e. $50 \%$ kernel density contour) compared with rapid transit locations (95\% kernel density contour) of Bugio petrels during the outward and return migrations. SST: sea surface temperature. $\mathrm{df}=1$ for all tests

\begin{tabular}{|c|c|c|c|c|}
\hline & $\begin{array}{l}\text { Stopover } \\
\text { areas }\end{array}$ & $\begin{array}{c}\text { Non-stopover } \\
\text { areas }\end{array}$ & $\chi_{1}^{2}$ & $\mathrm{p}$ \\
\hline \multicolumn{5}{|l|}{ Outward migration } \\
\hline Time of residence (d) & $4.32 \pm 2.12$ & $6.21 \pm 1.98$ & 7.24 & 0.01 \\
\hline Time on water (\%) & $69.2 \pm 3.33$ & $35.2 \pm 3.87$ & 17.20 & $<0.001$ \\
\hline Flight speed $\left(\mathrm{km} \mathrm{h}^{-1}\right)$ & $18.01 \pm 1.98$ & $27.10 \pm 1.11$ & 15.23 & $<0.001$ \\
\hline Mean travel distance ${ }^{a}(\mathrm{~km})$ & $192 \pm 31$ & $271 \pm 16$ & 16.31 & $<0.001$ \\
\hline Depth $(\mathrm{m})$ & $1423 \pm 492$ & $4188 \pm 195$ & 9.78 & 0.01 \\
\hline $\operatorname{SST}\left({ }^{\circ} \mathrm{C}\right)$ & $21.98 \pm 2.99$ & $22.56 \pm 2.15$ & 1.45 & 0.29 \\
\hline Chl $a\left(\mathrm{mg} \mathrm{m}^{-3}\right)$ & $1.89 \pm 0.11$ & $0.25 \pm 0.13$ & 16.22 & $<0.001$ \\
\hline Wind speed $\left(\mathrm{m} \mathrm{s}^{-1}\right)$ & $7.21 \pm 1.88$ & $7.44 \pm 2.10$ & 1.28 & 0.10 \\
\hline \multicolumn{5}{|l|}{ Return migration } \\
\hline Time of residence (d) & $5.14 \pm 2.77$ & $11.42 \pm 3.01$ & 10.01 & 0.01 \\
\hline Time on water (\%) & $60.23 \pm 2.87$ & $34.56 \pm 3.67$ & 15.91 & $<0.001$ \\
\hline Flight speed $\left(\mathrm{km} \mathrm{h}^{-1}\right)$ & $16.14 \pm 1.85$ & $27.01 \pm 2.06$ & 15.66 & $<0.001$ \\
\hline Mean travel distance ${ }^{a}(\mathrm{~km})$ & $178 \pm 19$ & $263 \pm 19$ & 14.12 & $<0.001$ \\
\hline Depth $(\mathrm{m})$ & $4025 \pm 478$ & $3156 \pm 676$ & 2.05 & 0.12 \\
\hline $\operatorname{SST}\left({ }^{\circ} \mathrm{C}\right)$ & $18.99 \pm 0.87$ & $22.67 \pm 1.45$ & 10.77 & 0.001 \\
\hline $\mathrm{Chl} a\left(\mathrm{mg} \mathrm{m}^{-3}\right)$ & $1.09 \pm 0.15$ & $0.34 \pm 0.13$ & 15.26 & $<0.001$ \\
\hline Wind speed $\left(\mathrm{m} \mathrm{s}^{-1}\right)$ & $7.23 \pm 1.89$ & $6.22 \pm 1.45$ & 11.34 & 0.001 \\
\hline
\end{tabular}




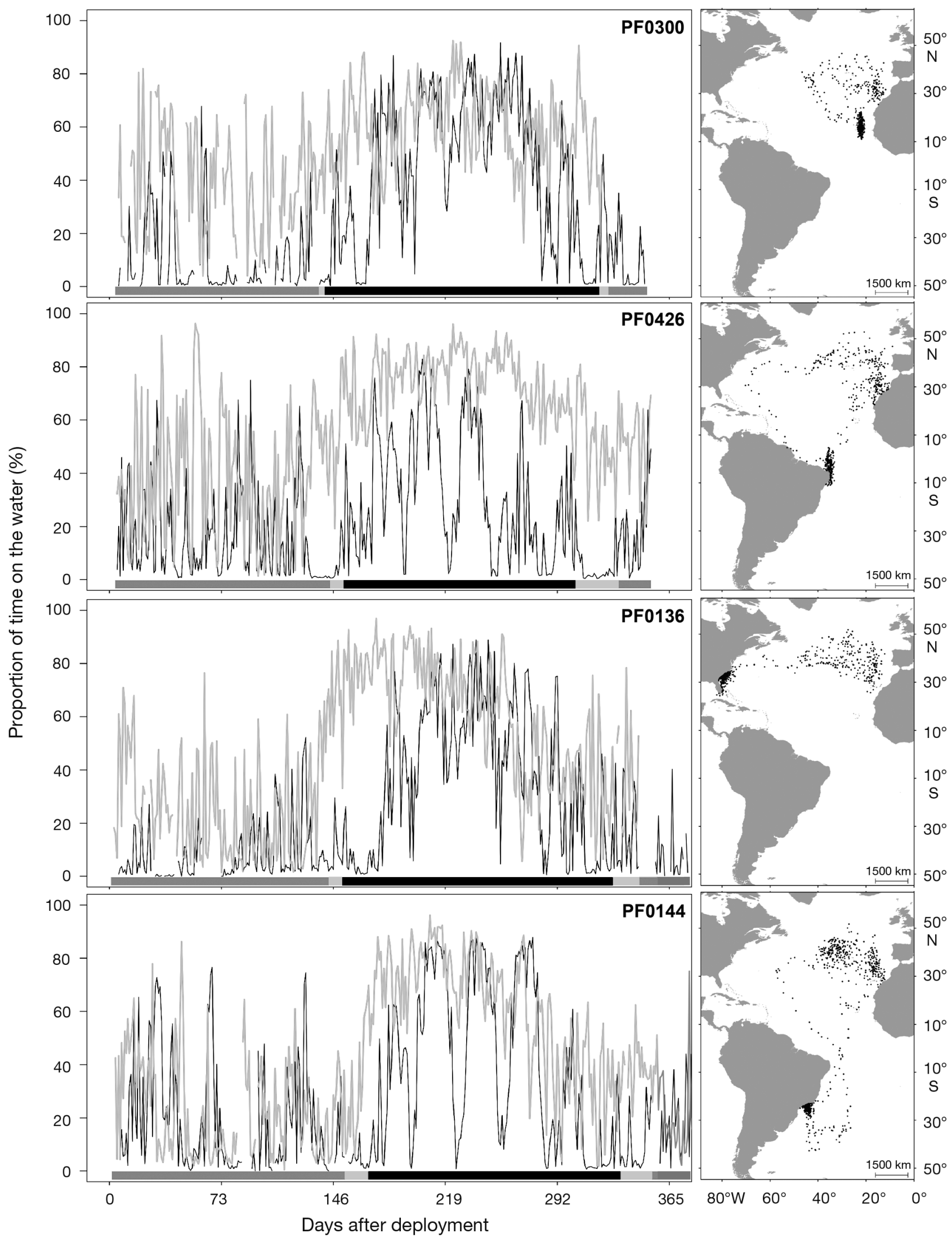

Fig. 4. (Above and following page.) Example activity patterns ( $\%$ of time on the water) during (grey line) day and (black line) night, and movements of individual Bugio petrels tracked from Bugio, Madeira, from 2007 to 2010 that wintered in one of 5 main areas. Dark grey bar: breeding phase, black bar: wintering phase, light grey bars: outward and return migrations (from left to right) 


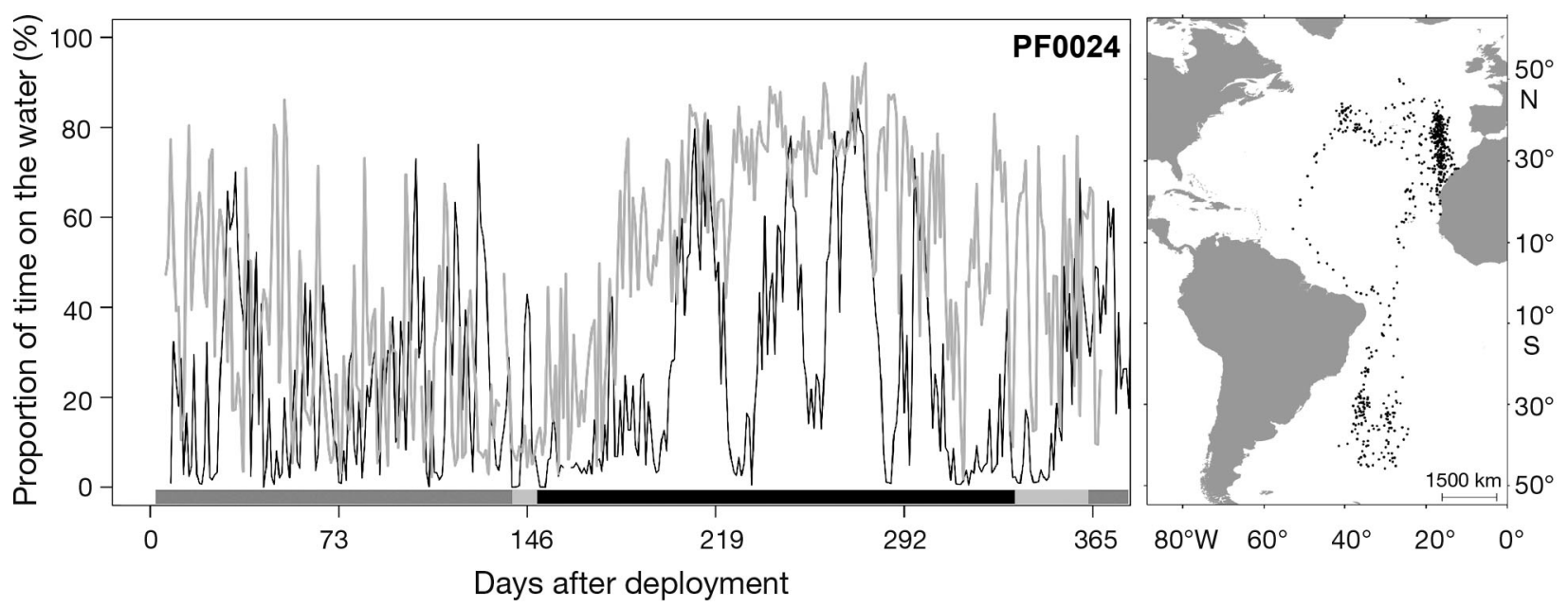

Fig. 4. (continued)

period: $\chi_{1}^{2}=15.93, \mathrm{p}<0.001$; breeding migration: $\chi_{1}^{2}$ $=20.16, \mathrm{p}<0.001$; wintering migration: $\chi_{1}^{2}=17.20, \mathrm{p}<$ $0.001)$. While in stopover areas during both the outward and return migrations, birds spent significantly greater time on the water and decreased flight speed; consequently, the distance between geolocation estimates was lower than outside these stopover regions (Table 2). Tracked birds spent a significantly greater proportion of time on the water during the wintering period (based on the GLMM: all day: $F_{3.835}=12.06$, p < 0.001 ; day period: $F_{3.835}=10.24, \mathrm{p}=0.001$; night period: $\left.F_{3.835}=15.22, \mathrm{p}<0.001\right)$ than during other periods of the year (Fig. 5A). Moreover, birds spent significantly more time on the water surface (night and day) from January to February (mid-winter) than from August to October (the incubation and chickrearing periods) (Fig. 5B). The proportion of time spent flying was therefore greater when birds had an egg or chick than during the non-breeding phase. Despite the higher proportion of time spent on water during winter, the birds exhibited a clear cyclic pattern of activity in relation to moon phase; the proportion of time birds spent on the water was positively correlated with the progression of full to new moon (Pearson's correlation, $\mathrm{r}=0.58$, df $=745, \mathrm{p}<0.001$ ). This means that those nights with a very low proportion of time on water (minimum of $6 \%$ ) coincided with full moon periods (e.g. see the black line for Bird PF0144 during the wintering phase in Fig. 4).

\section{DISCUSSION}

The present study reports for the first time the atsea distribution and activity of 17 Bugio petrels, and detailed information on their breeding schedule. Reported results are based on the data acquired using GLS devices deployed on this threatened species with a very small breeding population (160 to 180 breeding pairs; D. Menezes pers. comm.). Overall, the use of GLS devices on this particular population seems not to have affected the breeding outcome of tracked individuals ( $60 \%$ breeding success) in relation to non-tracked birds $(\sim 50 \%)$ and other Procellariiform breeders of the North Atlantic, such as Cory's shearwaters Calonectris diomedea ( 50\%; Ramos et al. 2003).

\section{Habitat use during the breeding stage}

During pre-laying and incubation, foraging excursions of Bugio petrels were very long (mean of $9.3 \pm 6.2 \mathrm{~d}$ ) and mostly confined to a specific oceanic region northeast of the Azores. Within this region, the birds used pelagic frontal regimes (both SSTG and CHLG work as proxies of frontal systems) in windy conditions and deep water (Table 1). This region (see area $a$ in Fig. 1) is located in the vicinity of the Sub-Polar Front, where cool and productive sub-Artic waters mix with warmer and less productive regimes of the central North Atlantic (Søiland et al. 2008). Research has just recently revealed the importance of this area as a hotspot of seabird biodiversity, with several seabird taxa foraging there during different phases of their annual cycle: Some species use this area as their main wintering ground (Sooty shearwaters Puffinus griseus: Hedd et al. 2012; black-legged kittiwakes Rissa tridactyla: González-Solís et al. 2011, Frederiksen et 

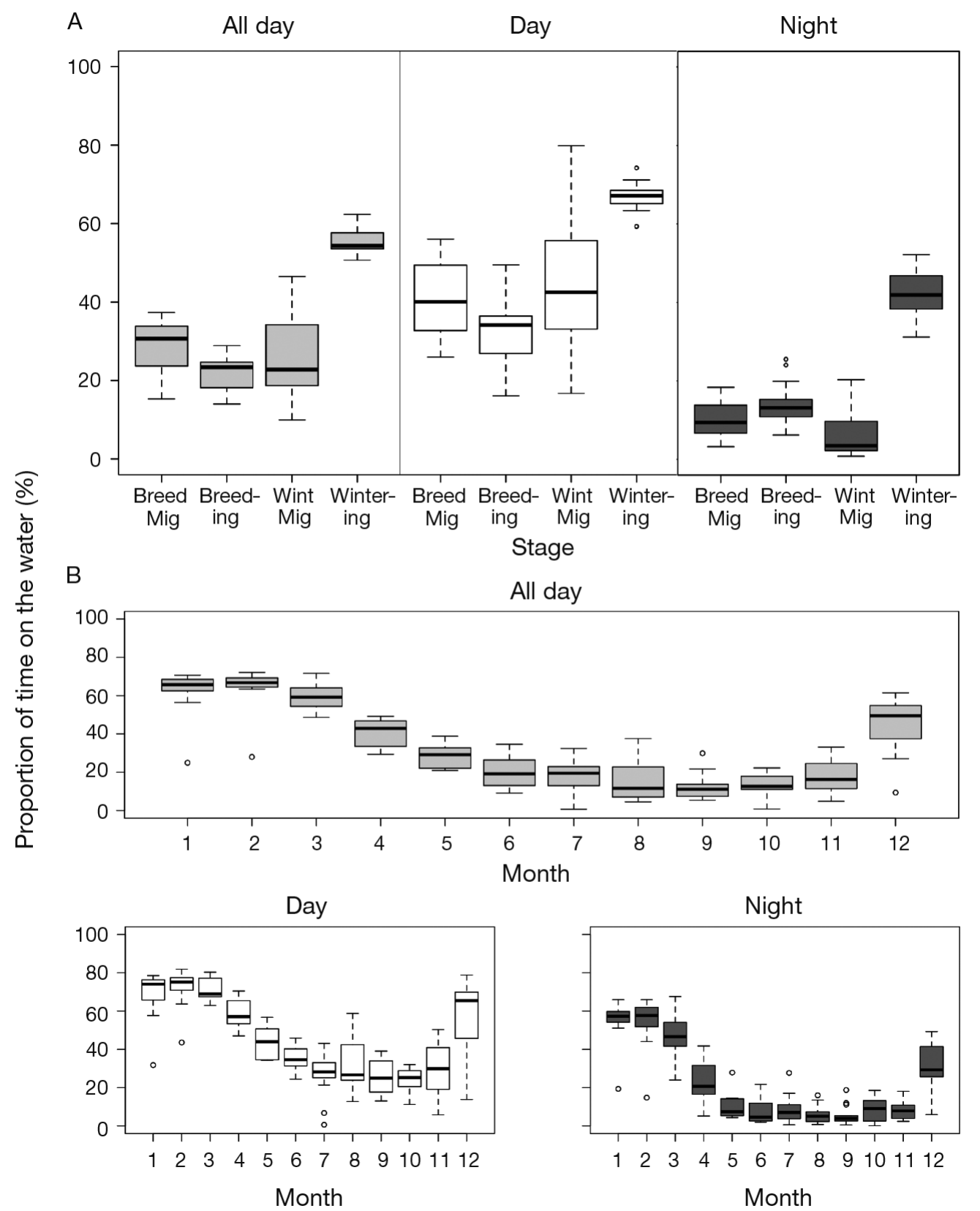

Fig. 5. At-sea activity of Bugio petrels tracked from Bugio, Madeira, from 2007 to 2010 during (A) different periods (i.e. phases of the life cycle) and (B) by month. Breed Mig: return migration, Wint Mig: outward migration. Boxplots represent median, 25 to $75 \%$ interquartile range and non-outlier range; points beyond are outliers

al. 2011) or as a migratory stopover (Artic terns Sterna paradisaea: Egevang et al. 2010; Cory's shearwaters: Roscales et al. 2011, Catry et al. 2011). Comparatively, Chatham petrels Pterodroma axillaris from the Pacific Ocean also relied on frontal regimes to forage during the pre-laying and incubation periods (Rayner et al. 2012). Those frontal regions were located 2000 to $3000 \mathrm{~km}$ southeast of the Chatham Islands, between the Subtropical
Convergence and Subantarctic Fronts, a similar distance to the one travelled by Bugio petrels to forage in the vicinity of the Sub-Polar Front $(\sim 2500 \mathrm{~km})$.

Bugio petrels showed a dual foraging strategy while provisioning their chick, similar to that of Cory's shearwaters from Desertas (Paiva et al. $2010 b)$, generally alternating short $(<3 \mathrm{~d})$ and long ( $>4$ d) trips, although with a slight preference for the 
latter. The main areas selected during chick-rearing were located north of Madeira or close to the Canary upwelling system at the northwest African coast and around the Cape Verde archipelago (Fig. 1). In this region, Bugio petrels preferred steeper and colder areas of high productivity, though windy regimes were not selected by the species anymore. Wind is directly linked to the energetic cost of foraging in seabirds (Weimerskirch et al. 2000). Our data suggest that Bugio petrels prefer areas with higher wind speed during pre-laying and incubation but not during chick-provisioning, perhaps because of the associated time and energetic cost if a strong headwind delays the return of the adult to feed the hungry chick. The at-sea area used by Bugio petrels during this stage seems to overlap with the distribution of Zino's petrels Pterodroma madeira from Madeira (Zino et al. 2011), Cory's shearwater Calonectris diometea from Desertas (Paiva et al. 2010a) and Selvagens (Paiva et al. 2010c), and Cape Verde shearwater Calonectris edwardsii from Cape Verde (Roscales et al. 2011). The African shelf area along the coast of Mauritania appears to be very important for populations of these 4 seabird species for part or all of the year and also for migrant seabirds from elsewhere, including Sabine's gull Larus sabini (Kopp et al. 2011), northern gannet Morus bassanus (Stenhouse et al. 2012), great skua Stercorarius skua (Magnusdottir et al. 2012) and south polar skua $S$. maccormicki (Fort et al. 2012). In fact, this area is within one of the most important large marine ecosystems in the world - the Canary Current-with strong and nutrient-rich upwelling, which naturally elevates primary productivity and progressively increases the abundance of plankton and small planktivorous pelagic fish, cephalopods and crustaceans, which ultimately attracts seabirds to the area (Mann \& Lazier 2006, Sherman \& Hempel 2009). The importance of this area as a resource and biodiversity hotspot means it should be considered as a high priority when designing any at-sea conservation strategy.

\section{Non-breeding distribution and habitat preferences}

Oceanographic characteristics slightly differed among wintering areas (Tables $1 \& 3$ ); those in the regions of the Southern Brazil Current and Northern Brazil Current, where most birds wintered, were characterised by steep bathymetric slopes and were closer to land, whereas the areas around the North Equatorial Current and Gulf Stream Current seem to have been selected because of low sea surface temperatures and high productivity, although the sea floor slope was also greater in the Gulf Stream Current and it was close to land (i.e. the continental shelf was narrower). Finally, the area of strictly oceanic waters used in the Central South Atlantic was very large, generally with deep waters and strong wind fields. Wind speed appeared to be less of a factor for non-breeding birds wintering in areas closer to Brazil (i.e. Northern Brazil Current and Southern Brazil Current, Fig. 1); however, there seems to be a major variable explaining the presence of birds in the Central South Atlantic: a large region of deep water where birds would benefit from strong winds for improving search efficiency (Table 1). Non-breeding Barau's petrels Pterodroma baraui in the Indian Ocean show even stronger selection for windy regions (Pinet et al. 2011b). Preliminary analysis of year-round tracking data from 12 individuals of the closely related Madeiran petrel (Zino et al. 2011) indicate that this species and Bugio petrels exhibit fairly distinctive migration strategies. Of the 2 species, the Bugio petrel is the more widely dispersed during the non-breeding period, with at least 1 individual moving to the eastern, western and central North and South Atlantic (Fig. 2). In contrast, non-breeding Madeiran petrels remained mostly in the East Atlantic from $40^{\circ} \mathrm{N}$ to $30^{\circ} \mathrm{S}$, with the exception of a small number of individuals that visited the northeast Brazilian coast (Zino et al. 2011). Bugio petrels are also more widely distributed and use a greater variety of habitats than

Table 3. Characterisation of the 5 main wintering grounds (50\% kernel density contour) selected by Bugio petrels. Values represent the mean $( \pm \mathrm{SD})$ inside individual $50 \%$ kernels during the non-breeding phase and excluding periods of migration

\begin{tabular}{|lccccc|}
\hline Main wintering grounds & Depth $(\mathrm{m})$ & $\mathrm{SST}\left({ }^{\circ} \mathrm{C}\right)$ & Chl $a\left(\mathrm{mg} \mathrm{m}^{-3}\right)$ & Wind speed $\left(\mathrm{m} \mathrm{s}^{-1}\right)$ & Distance to land $\left(\mathrm{km}^{2}\right)$ \\
\hline Gulf Stream Current & $129.4 \pm 45.7$ & $16.8 \pm 0.8$ & $3.7 \pm 0.4$ & $5.8 \pm 1.2$ & $97.5 \pm 48.7$ \\
North Equatorial Current & $222.4 \pm 89.4$ & $17.0 \pm 1.1$ & $2.8 \pm 0.5$ & $6.1 \pm 0.9$ & $114.5 \pm 54.9$ \\
North Brazil Current & $158.7 \pm 35.9$ & $21.1 \pm 1.2$ & $1.1 \pm 0.1$ & $4.9 \pm 1.1$ & $85.1 \pm 38.1$ \\
South Brazil Current & $138.9 \pm 47.8$ & $19.8 \pm 1.5$ & $0.4 \pm 0.2$ & $4.1 \pm 1.3$ & $78.2 \pm 24.8$ \\
Central South Atlantic & $975.2 \pm 245.9$ & $17.6 \pm 0.7$ & $0.5 \pm 0.8$ & $7.1 \pm 1.6$ & $1524.2 \pm 645.3$ \\
\hline
\end{tabular}


the Barau's petrel Pterodroma baraui from Réunion Island, which migrate east to a specific area of the central and eastern Indian Ocean (Pinet et al. 2011b). Similarly, the southern population of Cook's petrel P. cookii, tracked in New Zealand, migrated to a well-defined region and habitat type on the coastal upwelling regimes off Peru and California (Rayner et al. 2011). In contrast, the northern population was more spread from the eastern to northern Pacific (i.e. north of Hawaii) but still tightly concentrated within the distinct North Pacific convergence habitat (Rayner et al. 2011). Environmental regimes explaining the non-breeding distribution of Bugio petrels in coastal areas were similar to those of the southern population of Cook's petrel, which utilised habitats with low depth, low SST and high chl a concentration (Rayner et al. 2011). Chatham petrels also migrated toward the coast of Peru and Chile, but unlike Cook's petrels and the majority of wintering Bugio petrels, Chatham petrels spent their non-breeding period in a pelagic area $\sim 1000 \mathrm{~km}$ off the coast, which suggests some habitat segregation from the former related species (Rayner et al. 2012).

Four main stopover areas were identified for Bugio petrels, located around the Cape Verde archipelago, the northeast coast of Brazil, northwest of the Azores and off the north coast of Brazil. Specific stopover sites, where birds are assumed to recover lost body condition, have been identified for most long-distance migratory seabirds in the Atlantic (Guilford et al. 2009, Kopp et al. 2011, Stenhouse et al. 2012, present study). Immersion data for some of these species, including Cory's shearwater and Manx shearwater Puffinus puffinus, indicate that like Bugio petrels, birds in stopover areas reduce flight speed and increase the proportion of time on the water (Guilford et al. 2009, Dias et al. 2011, present study). Stopover analysis suggests that these areas are very important in terms of active foraging, where birds refuel before continuing on migrations to or from the colony. As such, these regions should be considered as an important area for management, as important as the core wintering areas. Although stopover regions used by Bugio petrels on their return migration tended to be windy, there was no such association during the outward migration. However, tracking data indicate that birds do not necessarily follow the shortest route, and conceivably any relationship could be blurred if progress is interrupted or birds are forced to detour because of the opening and closing of wind gates (González-Solís et al. 2009). Calm condi- tions or strong headwinds may also act as gates opening or closing migration corridors and appear to have a direct influence on the migration patterns of seabirds in the Atlantic (Felicísimo et al. 2008, Egevang et al. 2010). In fact, Bugio petrels seem to take advantage of the 'wind highways' (see Felicísimo et al. 2008) to cross the 'Equator wind gate' on their migration to the wintering grounds and again use the minimum cost 'highways' on their migratory route back to their breeding colony (González-Solís et al. 2009).

\section{Activity patterns}

Bugio petrels spent less time on the water during the breeding period, indicating more time spent actively searching for prey, presumably linked to the need to provision the chicks. During the non-breeding period, birds $(n=12)$ spent a significantly greater proportion of time on the water surface; this pattern could be directly linked to the fact that birds have a lower energetic demand during this period, and also to their moult. According to Bridge (2006), gadfly petrels will perform a 'simple descendent' moult, over a period of 3 to $4 \mathrm{mo}$, replacing its primary feathers sequentially during the non-breeding period. This also occurs in the Bugio petrel, (I. Ramirez pers. obs.) and other mid-North Atlantic species such as Calonectris diomedea (Raimos et al. 2009). During their resident non-breeding period, which is also part of their moulting period, birds could benefit from a sit and wait foraging strategy as described by Catry et al. (2004) or Rayner et al. (2008). However, there is no scientific evidence that moulting can affect feeding behaviour of the Bugio petrel or produce a flightless period. When compared to the known at-sea activity patterns of other Procellariiform species, such as white-chinned petrel Procellaria aequinoctialis (Mackley et al. 2011) or its near relative, the Chatham petrel Pterodroma axillaris (Rayner et al. 2012), Bugio petrels spent a higher proportion of time on water, especially during the chick-rearing period (in the case of the Chatham petrel). This may be indicative of a higher use of a 'sit and wait' technique by the Bugio petrel compared to the Chatham petrel. During the wintering period, both Chatham and white-chinned petrels exhibit similar values for their prevalence on the water surface, both during day and night $(\sim 70 \%)$. When compared to other larger Procellariidae, such as different species of albatrosses, the Bugio petrel presented activity patterns only similar to those of the grey-headed albatross 
Thalassarche chrysostoma (Mackley et al. 2010). With regard to the Bugio petrels' behaviour at night and its relation to the lunar cycle, we observed that these birds would spend more time in flight at night at times closer to the full moon; this is consistent with other species such as Barau's petrel Pterodroma baraui (Pinet et al. 2011a), the streaked shearwater Calonectris leucomelas (Yamamoto et al. 2008) and other larger species such as the white-chinned petrel Procellaria aequinoctialis (Mackley et al. 2011). Bugio petrels could benefit from the increased visibility caused by the full moon to actively search for prey, therefore shifting from their 'sit and wait' foraging behaviour to 'active foraging' during these special days. Another possibility is that upward migrations (to the surface) of their preferred prey could decrease during full-moon days, because they would be more exposed to predators. This could force the birds to search more actively for prey that otherwise could be reached with the sit and wait strategy. A third option is that the birds are directly affected by moonlight, as reported by Tarlow et al. (2003). Further research is needed to confirm which factor has the greatest influence on the Bugio petrel.

\section{Conservation implications}

The Bugio petrel is one of the rarest of European seabirds, with a very restricted breeding range. It is also an example of a species for which formerly serious land-based threats at the colony have been successfully mitigated or eliminated by careful management. At sea, the dispersed nature of the wintering distribution of the Bugio petrel has direct implications for the conservation of this rare species. First, it will be difficult to ensure effective management of such a large area by the requisite national and international authorities. Second, the distribution exposes the Bugio petrel population as a whole to a wider range of threats. However, the advantage of such a large breeding and nonbreeding range is that deterioration in conditions or some other factor affecting one area will have an impact on a small proportion of the population. Based on published studies, the gadfly petrels appear - with a few exceptions - to be at relatively low risk of incidental mortality in fisheries (e.g. Anderson et al. 2011) but could reduce prey abundance for Bugio petrels. Hence, increasing the level of fisheries monitoring and conducting more research on the feeding preferences of Bugio petrels are warranted.
Acknowledgements. We thank the Serviço do Parque Natural da Madeira for all their support throughout this study. Several Park wardens helped us to overcome the remoteness of Bugio's Island, and we are grateful to them for their friendship and support. We also thank SPEA Madeira and its Director, Isabel Fagundes, for her valuable support and fieldwork. This work was partly funded through the European Project LIFE06 NAT/P000184.

\section{LITERATURE CITED}

Anderson ORJ, Small CJ, Croxall JP, Dunn EK, Sullivan BJ, Yates O, Black A (2011) Global seabird bycatch in longline fisheries. Endang Species Res 14:91-106

Arcos J, Bécares J, Rodríguez B (2009) Áreas importantes para la conservación de las aves marinas. LIFE04NAT/ ES, Madrid

Bates D, Maechler M, Dai B (2008) Linear mixed-effects models using S4 classes. Version 0.999375-25

Block BA, Jonsen ID, Jorgensen SJ, Winship AJ and others (2011) Tracking apex marine predator movements in a dynamic ocean. Nature 475:86-90

Bridge ES (2006) Influences of morphology and behavior on wing-molt strategies in seabirds. Mar Ornithol 34: 7-19

Burnham K, Anderson D (2002) Model selection and multimodel inference: a practical information-theoretic approach. Springer, London

> Calenge C (2006) The package 'adehabitat' for the R software: a tool for the analysis of space and habitat use by animals. Ecol Model 197:516-519

> Catry P, Phillips R, Phalan B, Silk J, Croxall J (2004) Foraging strategies of grey-headed albatrosses Thalassarche chrysostoma: integration of movements, activity and feeding events. Mar Ecol Prog Ser 280:261-273

> Catry P, Dias MP, Phillips RA, Granadeiro JP (2011) Different means to the same end: long-distance migrant seabirds from two colonies differ in behaviour, despite common wintering grounds. PLoS ONE 6:e26079

Dias MP, Granadeiro JP, Phillips RA, Alonso H, Catry P (2011) Breaking the routine: individual Cory's shearwaters shift winter destinations between hemispheres and across ocean basins. Proc Biol Sci 278:1786-1793

Egevang C, Stenhouse IJ, Phillips RA, Petersen A, Fox JW, Silk JRD (2010) Tracking of Arctic terns Sterna paradisaea reveals longest animal migration. Proc Natl Acad Sci USA 107:2078-2081

Felicísimo ÁM, Muñoz J, González-Solís J (2008) Ocean surface winds drive dynamics of transoceanic aerial movements. PLoS ONE 3:e2928

Fort J, Pettex E, Tremblay Y, Lorentsen SH and others (2012) Meta-population evidence of oriented chain migration in northern gannets (Morus bassanus). Front Ecol Environ 10:237-242

Frederiksen M, Moe B, Daunt F, Phillips RA and others (2011) Multicolony tracking reveals the winter distribution of a pelagic seabird on an ocean basin scale. Divers Distrib 18:530-542

> González-Solís J, Felicísimo A, Fox J, Afanasyev V, Kolbeinsson Y, Muñoz J (2009) Influence of sea surface winds on shearwater migration detours. Mar Ecol Prog Ser 391:221-230

González-Solís J, Smyrli M, Militão T, Gremillet D, Tveraa T, Phillips R, Boulinier T (2011) Combining stable isotope 
analyses and geolocation to reveal kittiwake migration. Mar Ecol Prog Ser 435:251-261

- Guilford T, Meade J, Willis J, Phillips RA and others (2009) Migration and stopover in a small pelagic seabird, the Manx shearwater Puffinus puffinus: insights from machine learning. Proc Biol Sci 276:1215-1223

Hedd A, Montevecchi W, Otley H, Phillips R, Fifield D (2012) Trans-equatorial migration and habitat use by sooty shearwaters Puffinus griseus from the South Atlantic during the nonbreeding season. Mar Ecol Prog Ser 449: 277-290

Jesus J, Menezes D, Gomes S, Oliveira P, Nogales M, Brehm A (2009) Phylogenetic relationships of Gadfly petrels Pterodroma spp. from the Northeastern Atlantic Ocean: molecular evidence for specific status of Bugio and Cape Verde petrels and implications for conservation Bird Conserv Int 19:199-214

Kopp M, Peter H, Mustafa O, Lisovski S, Ritz M, Phillips R, Hahn S (2011) South polar skuas from a single breeding population overwinter in different oceans though show similar migration patterns. Mar Ecol Prog Ser 435: 263-267

Mackley E, Phillips R, Silk J, Wakefield E, Afanasyev V, Fox J, Furness R (2010) Free as a bird? Activity patterns of albatrosses during the nonbreeding period. Mar Ecol Prog Ser 406:291-303

Mackley EK, Phillips RA, Silk JRD, Wakefield ED, Afanasyev V, Furness RW (2011) At-sea activity patterns of breeding and nonbreeding white-chinned petrels Procellaria aequinoctialis from South Georgia. Mar Biol 158: 429-438

MacLeod CJ, Adams J, Lyver P (2008) At-sea distribution of satellite-tracked grey-faced petrels, Pterodroma macroptera gouldi, captured on the Ruamaahua (Aldermen) islands, New Zealand. Pap Proc R Soc Tasman 142: 73-88

Magnusdottir E, Leat EHK, Bourgeon S, Strøm H and others (2012) Wintering areas of Great Skuas Stercorarius skua breeding in Scotland, Iceland and Norway. Bird Study 59:1-9

Mann K, Lazier J (2006) Dynamics of marine ecosystems: biological-physical interactions in the oceans. WileyBlackwell, Oxford

Menezes D, Oliveira P, Ramírez I (2010) Pterodromas do arquipélago da Madeira, duas espécies em recuperação. Serviço do Parque Natural da Madeira, Funchal

Paiva VH, Geraldes P, Ramírez I, Meirinho A, Garthe S, Ramos JA (2010a) Oceanographic characteristics of areas used by Cory's shearwaters during short and long foraging trips in the North Atlantic. Mar Biol 157: 1385-1399

Paiva VH, Geraldes P, Ramírez I, Meirinho A, Garthe S, Ramos JA (2010b) Foraging plasticity in a pelagic seabird species along a marine productivity gradient. Mar Ecol Prog Ser 398:259-274

> Paiva VH, Geraldes P, Ramírez I, Garthe S, Ramos JA (2010c) How area restricted search of a pelagic seabird changes while performing a dual foraging strategy. Oikos 119:1423-1434

Phalan B, Phillips RA, Silk J, Afanasyev V and others (2007) Foraging behaviour of four albatross species by night and day. Mar Ecol Prog Ser 340:271-286

Phillips RA, Xavier JC, Croxall JP, Burger A (2003) Effects of satellite transmitters on albatrosses and petrels. Auk 120: 1082-1090
Phillips R, Silk J, Croxall J, Afanasyev V, Briggs D (2004) Accuracy of geolocation estimates for flying seabirds. Mar Ecol Prog Ser 266:265-272

Pinet P, Jaeger A, Cordier E, Potin G, Le Corre M (2011a) Celestial moderation of tropical seabird behavior. PLoS ONE 6:e27663

Pinet P, Jaquemet S, Pinaud D, Weimerskirch H, Phillips R, Le Corre M (2011b) Migration, wintering distribution and habitat use of an endangered tropical seabird, Barau's petrel Pterodroma baraui. Mar Ecol Prog Ser 423: 291-302

> Pinet P, Jaquemet S, Phillips RA, Le Corre M (2012) Sex-specific foraging strategies throughout the breeding season in a tropical, sexually monomorphic small petrel. Anim Behav 83:979-989

R Development Core Team (2011) R: a language and environment for statistical computing. R Foundation for Statistical Computing, Vienna

Ramírez I, Geraldes P, Meirinho A, Amorim P, Paiva V (2008) Important areas for seabirds in Portugal. LIFE04 NAT/ PT/000213, Lisboa

> Ramos JA, Moniz Z, Solá E, Monteiro LR (2003) Reproductive measures and chick provisioning of Cory's shearwater Calonectris diomedea borealis in the Azores: timing of breeding influenced wing-length at fledging, and egg size may be an indicator of fledging weight and the amount of food received by chicks. Bird Study 50:47-54

Ramos R, Militão T, González-Sólis J, Ruiz X (2009) Moulting strategies of a long-distance migratory seabird, the Mediterranean Cory's Shearwater Calonectris diomedea diomedea. Ornithology 151:151-159

- Rayner M, Hauber M, Clout M, Seldon D, Van Dijken S, Bury S, Phillips R (2008) Foraging ecology of the Cook's petrel Pterodroma cookii during the austral breeding season: a comparison of its two populations. Mar Ecol Prog Ser 370:271-284

Rayner MJ, Hartill BW, Hauber ME, Phillips RA (2010) Central place foraging by breeding Cook's petrel Pterodroma cookii: foraging duration reflects range, diet and chick meal mass. Mar Biol 157:2187-2194

Rayner MJ, Hauber ME, Steeves TE, Lawrence HA and others (2011) Contemporary and historical separation of transequatorial migration between genetically distinct seabird populations. Nat Commun 2:332-337

> Rayner MJ, Taylor GA, Gummer HD, Phillips RA, Sagar PM, Shaffer SA, Thompson DR (2012) The breeding cycle, year-round distribution and activity patterns of the endangered Chatham petrel (Pterodroma axillaris). Emu 112:107-116

> Roscales J, Gómez-Díaz E, Neves V, González-Solís J (2011) Trophic versus geographic structure in stable isotope signatures of pelagic seabirds breeding in the northeast Atlantic. Mar Ecol Prog Ser 434:1-13

Sherman K, Hempel G (eds) (2009) The UNEP large marine ecosystem report: a perspective on changing conditions in LMEs of the world's regional seas. UNEP Regional Seas Reports and Studies, Nairobi

Søiland H, Budgell WP, Knutsen $\varnothing$ (2008) The physical oceanographic conditions along the Mid-Atlantic Ridge north of the Azores in June-July 2004. Deep-Sea Res II 55:29-44

Stenhouse IJ, Egevang C, Phillips RA (2012) Trans-equatorial migration, staging sites and wintering area of Sabine's gulls Larus sabini in the Atlantic Ocean. Ibis 154:42-51 
Tarlow EM, Hau M, Anderson DJ, Wikelski M (2003) Diel changes in plasma melatonin and corticosterone concentrations in tropical Nazca boobies (Sula granti) in relation to moon phase and age. Gen Comp Endocrinol 133: 297-304

Weimerskirch H, Guionnet T, Martin J, Shaffer SA, Costa DP (2000) Fast and fuel efficient? Optimal use of wind by flying albatrosses. Proc R Soc Lond B 267:1869-1874

Yamamoto T, Takahashi A, Yoda K, Katsumata N, Watanabe

Editorial responsibility: Jacob González-Solís,

Barcelona, Spain
S, Sato K, Trathan PN (2008) The lunar cycle affects at-sea behaviour in a pelagic seabird, the streaked shearwater, Calonectris leucomelas. Anim Behav 76: 1647-1652

Zino F, Phillips R, Biscoito M (2011) Zino's petrel movements at sea-a preliminary analysis of datalogger results. Birding World 24:216-219

Zuur A, Ieno E, Smith G (2007) Analysing ecological data. Springer, New York, NY

Submitted: April 16, 2012; Accepted: September 29, 2012

Proofs received from author(s): February 11, 2013 